\title{
KERK EN KEISER BY NICEA
}

\author{
PROF. DR. A. D. PONT
}

\section{Inleidende Opmerkings}

By die herdenking van die eerste ekumeniese konsilie wat te Nicea gehou is in 325, nou 1650 jaar gelede, is die opvallende dat keiser Konstantyn daar so ' $n$ belangrike rol gespeel het. Dit word duidelik in die beskrywing wat Eusebius gegee het van 'n feesmaal wat die keiser aan die biskoppe angebied het: ${ }^{1}$ )

„Geen biskop het aan die tafel van die keiser ontbreek nie. Daar het hulle gelê op dieselfde kussings as die keiser. Ander het op kussings, weerskante van die keiser, gelê. Byna kon mens dit sien as ' $n$ beeld van die Koninkryk van Christus en mens het gedink dat dit eerder ' $n$ droom as 'n werklikheid was."

As dié vredige beeld, wat by Nicea moontlik geword het, ' $n$ droom was. dan was dit in ieder geval van redelik korte duur. Want die keiser en die biskoppe van die kerk het nie gou weer die geleentheid gevind om so in eensgesindheid saam te eet nie en relatief gou het die werklikheid ook Eusebius oortuig dat die Koninkryk van Christus nie gebou word deur biskoppe wat op die keiserlike kussings ontspan nie. Tog was hierdie gebeure wat by Nicea moontlik geword het, wel 'n uitsonderingsituasie, want voor Konstantyn was die verhouding tussen die kerk en die keiser gladnie so gunstig vir die kerk nie.

\section{Die Situasie voorafgaande aan Nicea}

Die posisie van die kerk in die Romeinse Ryk voor Konstantyn word dikwels voorgestel as die tyd toe die christengelowiges slegs die stilles in die land was wat hierdie wêreld vermy het en alleen die komende Heer van kerk en wêreld verwag het. ${ }^{2}$ ) Tog is dit ' $n$ effens simplistiese siening, want die houding van die kerk teenoor die keiser kan alleen werklik gepeil word as die negatiewe en die positiewe houding teenoor die keiser in aanmerking geneem word. As die kerk, verlos van die vervolging deur dia keiser, 'n standpunt moet inneem teen die keiser wat die staatskerk wil gebruik én misbruik, dan is dit duidelik dat daar al heelwat aandag aan die kwessie van die verhouding tussen die kerk en die keiser gegee is. Om die nuwe situasie wat by Nicea so duidelik na vore kom by die keiserlike feesmaal na waarde te skat, moet 'n oomblik na die voorafgaande tyd gekyk word.

1) Eusebius, Vita Constantini, III, 15.

2) Vg. E. Stauffer, Christus und die Cäsaren, Hamburg 1952; 0. Cullmann, Der Staat im Neuen Testament, Tübingen 1956; E. Lohmeyer, Christuskult und Kaiserkult, Tübingen 1919. 
Dat die keiser en die wêreldlike staat negatief deur die Christendom beoordeel is, lyk baie vanselfsprekend, want die Christene is die volgelinge van Jesus Christus wat 'n ryk proklameer wat nie van hierdie wêreld is nie (Joh. 18:36). Daarby staan die vroeë kerk in ' $n$ wêreld waar sy kontak met die keiser begin met Nero se menslike fakkels in sy tuin en eindig met Diocletianus se bloedige vervolginge. Verder is dit so dat die apostels ook antiteties teenoor die keiser staan, en clit is dan ook nie vreemd dat Hippolytus in sy Daniëlkommentaar IV. 9 na die keiserryk verwys as 'n ryk wat sy bestaansmoontlikheid van die Satan kry nie.

Die rede waarom die vroeë kerk antiteties teenoor die keiser en die staat staan, is omdat vanaf Augustus die keiser in die wêreld staan as die pontifex marimus, die opperpriester van die Romeinse staatsgodsdiens. Hoewel in die latere Romeinse ryk dié aanspraak vervlak het, is dit tog so dat die pretensie altyd bly staan het dat die keiser-staat 'n absolute reg het om ook die godsdiens van die onderdane te reël. Hierdie hele aanspraak van die keiser-staat is deur die kerk afgewys én ontken.

Daarby het 'n tweede faktor gekom. Vanaf die tyd van Julius Caeser kom uit die Hellenistiese Ooste van die ryk die goddelike verering van die keiser as die heiland en redder van sy onderdane na vore. Die keiser, so is geoordeel, is die sigbaar geworde mag van god, is self god. Vanaf Augustus dan, gebeur dit dat die afgestorwe keiser, by wyse van 'n Senaatsbesluit, onder die gode opgeneem word. Maar Septimus Severus is dan die eerste wat homself al tydens sy lewe as 'n god laat vereer. Diocletianus, wat homself die waardighede van Jupiter toeëien, toon hoe ver hierdie verpolitiseerde godsdiens en vroomheid kan gaan.

Teenoor hierdie ontwikkeling het die kerk en die Christene skerp afwysend gestaan en ten ene male geweier om óf die keiser as god te erken óf om hom goddelike eer te bewys. Interessant is egter die opvatting van die apologeet Justinus wat in 150, na aanleiding van die bevel van Christus om aan die keiser te gee wat die keiser toekom, duidelik stel dat alhoewel hy 'n gehoorsame staatsburger is en wil wees, sal hy alléén God aanbid. Daarby gaan hy verder en wys die keiser, as heerser, of sy verantwoordelikheid voor God én op die ewige straf wat op die slegte heerser wag.

Dieselfde argument vind mens terug by Theophilus, biskop van Antiochië, by Tertullianus, Hippolytus en ook by Origines. By almal is die afwysing van die aansprake van die keiser slegs die keersy van die aanvaarding van die vervolging en martelaarskap, die oorwinning in Christus, die Heer wat die wêreld oorwin het. Dit is egter duidelik dat in die vroeë kerk die keiser-staat alleen dán afgewys 
word wanneer dié aansprake die trou wat die Christengelowige aan die hemelse koninkryk van God verskuldig is, in gevaar stel. Daarom was daar ook 'n positiewe waardering van die staat, al was dit soms maar betreklik, moontlik in die vroeë kerk.

\section{Die positiewe waardering van die verhouding met die keiser on die staat}

Van die begin af was dit vir die Christelike kerk duidelik dat die staatsgesag, soos dit in die keiser beliggaam is, 'n gegewene van God is. Dat Paulus se opmerkings in Rom. 13 nié 'n latere interpolasie is nie, soos soms wel beweer word, blyk duidelik uit Dan. 2:37 en ook uit die Wysheidsliteratuur, waar die gesag van die koning na God teruggevoer word. ${ }^{3}$ ) In Origines se Romeinekommentaar word dié saak duidelik uitgelê: die gelowiges moet aan die keiser gee wat aan die keiser toekom en daarmee ontstaan dan die spreuk: Eer die keiser omdat hy keiser is maar aanbid alléén God!

Die duidelikste spreek hierdie opvatting seker uit die liturgiese gebed vir die keiser en die staat wat Clemens Romanus ongeveer 96 , in die dae van Keiser Domitianus, in sy brief aan die gemeente in Korinthe toevoeg. Daarvolgens het die gemeente gebid:

,Heersersgesag het $U$ hulle gegee. Laat ons, o Heer, aan $u$ almagtige en heilige Naam en aan ons heersers en leiers op aarde gehoorsaam wees."

Hierdie gebed is miskien die duidelikste bewys van die positiewe waardering wat daar in die vroeë kerk was vir die keiser-staat, al het die keiser die gelowiges ook met bloedige vervolgings geteister.

Opvallend is ook Origines se uitspraak in sy strydskrif teen Celsus, II, 30:

,In die dae van Jesus is die geregtigheid gevestig en 'n volheid van vrede wat met sy geboorte begin het. God het die volkere vir sy leer voorberei en het dit beskik dat hulle almal onder die heerskappy van die een romeinse keiser gekom het. Daar sou nie 'n vaelheid van konings wees nie want dan het die volkere vreemd teenoor mekaar gestaan en dan was die uitvoering van Jesus se bevel: gaan heen en leer alle volkere, wat $\mathrm{Hy}$ aan die apostels gegee het, baie moeiliker. Jesus is gebore, soos mens weet, onder die regering van Augustus, wat die grootste meerderheid van mense wat op die aarde geleef het, deur een, enkelvoudige koninkryk as 't ware gelykgemaak het."

Hier word Augustus gesien as 'n wegbereider van Jesus Christus en die keiserryk as 'n hulp vir die kerk. Dit is 'n merkwaardige uitspraak veral as bedink word dat Origines leef in ' $n$ tyd wanneer die Christenvervolgings nog lank nie uitgewoed is nie.

3) H. Windisch, Imperium und Evangelium, Kiel 1931. 
Tertullianus en ook ander Christelike skrywers wys verder daarop dat die kerk die keiser eer as ' $n$ mens wat, ná God, die tweede in belangrikheid is maar nogtans ' $n$ mens, wat alles wat hy is, van God ontvang het en daarom klaarblyklik minder as God is. Maar terselfdertyd is die gebed van die kerk vir die staat en die keiser een van die redes van die uitstel van die einde van die wêreld en in dié sin onderhou die Christene ook die ryk in die wêreld.

Terselfdertyd word dit egter ook duidelik dat die uitbreiding van die kerk vir die Romeinse owerhede groot probleme geskep het. Geleidelik word die kerk, alleen al deur sy getalle, ' $n$ faktor waarmee die keisers terdeë rekening moet hou. So gebeur dit dat keiser Philippus Arabs in die jare 244-249 met Origines in verbinding tree en dit is waarskynlik ook die rede daarvoor dat keiser Maximus in die jare 235-238 die vervolginge tot die biskoppe, die leiers van die kerk, beperk. Cyprianus wys in 251 daarop dat die biskop van Rome, in sy botsings met die keiser. al oorwinnings behaal het. Geleidelik begin die kerk die oorhand kry.

Keiser Gallienus, 260-268, is die eerste keiser wat direk in gesprek met die kerk tree wanneer hy aan die biskoppe skryf dat hy die edik van Decius ophef waarvolgens alle kerklike eiendomme gekonfiskeer word. Nog verder gaan dit wanneer keiser Aurelianus genader word om te help wanneer Paulus van Samosata weens kettery afgesit word en nie sy biskopsetel wil prysgee nie. Deur die bystand van die keiser word Paulus tog effektief afgesit. Hier tree die heidense keiser op as die helper van die kerk..4) Geleidelik groei owerheid en kerk nader na mekaar toe en die laaste skerp vervolginge onder Diocletianus en Galerius kan die proses nie meer stuit nie. In sy edik van 311, wat hy op sy sterfbed uitvaardig, sê Galerius: ${ }^{5}$ )

.Hulle mag weer Christene wees en die geboue waarin hulle saamkom, weer herbou onder die voorwaarde egter dat hulle op geen manier teen die staatsinrigting optree nie."

Dit was vir die kerk geen probleem nie want die kerk het nooit vyandig teen die keiser of die staat opgetree nie. Die beste kan dié situasie wat bestaan het voor Konstantyn, deur ' $n$ aanhaling van Origines aangedui word. Hy het gestel: ${ }^{6}$ )

"Die Christene bewys aan hulle vaderland meer weldade as al die ander mense. Hulle is leersame voorbeelde vir die ander staatsburgers omdat hulle leer om aan dié God trou te wees wat ook oor die staat staan. So trek hulle hulle medeburgers saam na daardie geheimenisvolle hemelstaat omdat hulle in hierdie klein, aardse

4) Eusebius, Historia Ecclesiastica, VII, 30.

5) Eusebius, Historia, VIII, 17.

•) Origines, Contra Celsum, VIII, 74. 
staat 'n goeie, sedelike lewe gevoer het. Van hierdie Christene kan mens sê: Welaan, julle was in die klein staatjie trou gewees, gaan nou in die groot staat."

\section{Keiser Konstantyn}

Die verhouding van die kerk en die keiser-staat het geleidelik in die rigting van ' $n$ samegaan beweeg en daarom was die gesamentlike proklamasie van die twee keisers, Konstantyn en Licinius, in 313 te Milaan ook nie so vreemd nie. Daar word gestel: ${ }^{7}$ )

.Daarom is ons van mening dat die volgende besluit in ooreenstemming met gesonde en suiwer redenering is $\mathrm{nl}$. dat niemand wat die Christelike oortuiging aanvaar het of enige ander oortuiging wat na sy mening hom pas, verplig moet word om sy oortuiging te verloën nie sodat die Opperste Godheid (summa divinitas), wat ons ook dien, ons in alle dinge kan bystaan met sy genade en goedgesin dheid."

Met hierdie versigtig bewoorde edik wat nog nie 'n Christelike edik genoem kan word nie, het die kerk sy vryheid in die Romeinse ryk gekry. Die kerk self het hierdie proklamasie gesien as die erkenning van die bestaansreg waarop die kerk geduldig gewag het. Die keiser het met hierdie erkenning geen toegewing gemaak nie, hy het slegs sy plig, soos God dit hom opgedra het, vervul. So het eeue se stryd gelei tot erkenning, tot verdraagsaamheid. Maar dit sou nie daarby bly nie. Daarom het hierdie edik van Milaan vir die kerk nie net voordele gebring nie.

Om dit ' $n$ oomblik te $\in$ valueer, moet aandag gegee word aan die persoon van keiser Konstantyn, want Konstantyn as keiser gee ' $n$ nuwe wending aan die geskiedenis van kerk en wêreld en hy is één van die groot keerpunte in die loop van die wêreldgeskiedenis.

Konstantyn is die seun van Constantius Chlorus, caesar van die Westerse deel van die ryk, ondergeskik aan die Augustus, Maximianus Herculius. Konstantyn self het egter in die Ooste grootgeword onder Augustus Diocletianus en caesar Galerius. In 305 word Constantius Chlorus Augustus saam met Galerius in die Ooste, na die troonafstand van Maximianus en Diocletianus. $\mathrm{Na}$ Constantius Chlorus se dood roep die leër Konstantyn uit tot Augustus in die Weste maar Maximianus gryp dan self weer na die mag en word deur Konstantyn verslaan. Sy seun, Maxentius, sluit dan ' $n$ verbond met die caesar van die Ooste, Maximinus, in ' poging om Konstantyn te weerstaan. Konstantyn bring sy leërs dan na Italië om die sterk magte van Maxentius aan te durf. In 'n reeks van verbluffende veldslae vernietig Konstantyn Maxentius se magte en slaag daarin om Rome, war as 'n onverowerbare vesting beskou

i) Lactantius, De Mortibus Persecutorum. 
is, in te neem en Maxentius finaal te verslaan. Daarop word Konstantyn deur die Senaat as die onbetwisbare Augustus gehuldig.

Dit is tydens sy veldtog teen Maxentius, so vertel Eusebius, ${ }^{8}$ ) dat Konstantyn die visioen gesien het van 'n kruis, dwarsoor die son met die opdrag daarby dat hy in dié teken sal oorwin. Verder het Konstantyn voor die mure van Rome ' $n$ tweede visioen gesien wat hom opdrag gegee het om die Christusmonogram op die skilde van sy soldate aan te bring. Of al hierdie gebeure historiese feite is, is ' $n$ saak wat al dekades lank bespreek word. Die feit bly egter dat hierin duidelik word dat Konstantyn die Christelike geloof aangeneem het, en dat hy dus, wat die godsdiens betref, hom assosieer en identifiseer met ' $n$ minderheidsgroep in sy ryk, want die Christelike kerk tel dan waarskynlik nie meer as $10 \%$ van die totale bevolking nie.

Onmiddellik nadat hy Augustus in die Weste geword het, bepaal Konstantyn dat alle vervolgings gestaak sal word, terwyl hy terselfdertyd, dit wil sê in 312, opdrag gee dat in die provinsie Africa alle besittings wat vroeër aan die kerk behoort het, weer aan die kerk gegee moet word. 'n Bietjie later kry die pro-consul in Africa 'n verdere opdrag, $\mathrm{nl}$. om toe te sien dat die clerus vrygestel sal word van die munera civilia. In sy opdrag stel Konstantyn dat die onderbreking van die kerk se godsdiensoefening die ryk benadeel het terwyl die voortgang van die Christelike gods diensoefening

..... tot gevolg gehad het 'n besondere goeie geluk vir die Romeinse staat en ' $n$ besondere voorspoed in alle menslike aangeleenthede, wat alles aan die goddelike goedgesindheid te danke is."

Alleen hieruit is dit al duidelik dat daar by Augustus Konstantyn meer aanwesig is as net verdraagsaamheid teenoor die Christelike godsdiens. Die priesters van die kerk is, soos Konstantyn dit sien, ook besig om die voorspoed en welvaart van die ryk te verstewig. Om dit in moderne taal te stel: hier word die kerk gesien as ' $n$ stutorganisasie in en van die ryk.

In Februarie 313 ontmoet Konstantyn en Licinius mekaar te Milaan en daar word dan besluit op die edik van Milaan, ' $n$ beleid van volledige godsdiensvryheid terwyl elke Christelike kerk as ' $n$ regspersoon erken word.") Licinius dra dan na die Ooste dieselfde beleid van verdraagsaamheid, erkenning en herstel van gekonfiskeerde besittings ten opsigte van die kerk wat Konstantyn vanaf 311 reeds in die Weste toegepas het.

8) Eusebius, Vita, I, 26.

9) Hoewel die vraag bestaan of daar 'n formele dokument, die Edik van Milaan, bestaan, hoef oor die feite wat daarin vervat is en die beleid wat daar neergelê is, nie getwyfel te word nie. 
Kort na Konstantyn se groot oorwinning oor Maxentius by die Pons Milvius, doen die Donatiste van Noord-Afrika 'n beroep op Konstantyn. Die Donatiste is deur Konstantyn uitgesluit uit die keiserlike goedgunstigheid wat aan die kerk bewys is. Daarop het die Donatiste Konstantyn gevra om te bemiddel om hulle verskille met die kerk by te lê en op te los. Op hulle versoek stel Konstantyn drie biskoppe uit Gallië saam met die biskop van Rome en 'n sekere Marcus aan om tien verteenwoordigers van die kerk en tien verteenwoordigers van die Donatiste aan te hoor en oor dié saak uitsluitsel te gee. Die biskop van Rome wysig egter die samestelling van hierdie kerklike regbank deur veertien Italiaanse biskoppe toe te voeg en so die Konstantynse regbank te omvorm tot 'n sinode. Die kerklike praktyk neem dus hier die voortou.

$\mathrm{Na}$ hierdie ondersoek word die uitspraak teen die Donatiste gegee en biskop Caecilianus van Kartago word in die gelyk gestel. Die Donatiste protesteer egter weer en op grond daarvan roep Konstantyn die Konsilie van Arles byeen om nou finaal uitsluitsel te gee. Interessant is Konstantyn se skrywe aan die pro-consul in Africa om hierdie reëling te bevestig. Daar stel Konstantyn:

„Ek is nie van oordeel dat dit korrek is dat verskille en strydpunte van hierdie aard van my weggehou moet word nie omdat God miskien op grond daarvan teen die hele menslike geslag en ook teen my kan optree aan wie $\mathrm{Hy}$, deur sy Goddelike beslissing, die bestuur van alle menslike sake toevertrou het sodat God in sy toorn nie dalk anders mag beskik as tot hiertoe nie."

Hierdie skrywe is insiggewend, want hieruit blyk dit dat Konstantyn die eenheid van die kerk sien as 'n saak wat direk aan die keiser toevertrou is en waarin die keiser ook ' $n$ verantwoordelikheid het. Die keiser neem dus hier 'n beslissing wat vir die kerk van groot gewig is sonder dat die kerk oor die aangeleentheid geraadpleeg is.

Die Konsilie van Arles bevestig die uitspraak van die biskop van Rome maar ook dié uitspraak wil die Donatiste nie aanvaar nie, en appelleer na die keiser self. Hy handhaaf egter die uitspraak van die Konsilie, want na lang onderhoude met Donatus en Caecilianus in Italië besluit Konstantyn in November 316 om alle Donatistekerkgeboue te konfiskeer en om die Donatiste met geweld te onderdruk. Na vier jaar van vervolging erken Konstantyn dat dit nie die gewenste resultate gehad het nie en laat hy die schismatici maar oor aan die oordeel van God.

Dit is belangrik om daarop te let dat die Konsilie van Arles, die eerste Konsilie wat die vrygeworde kerk in die Romeinse ryk hou, op bevel van Konstantyn saamkom. Konstantyn begin hier 
'n pad betree waarop die keiser al meer en meer in sacra intree en die kerk aanvaar hierdie keiserlike optrede, en so skep keiser én kerk 'n opening waarvoor die kerk 'n duur prys sou betaal.

Konstantyn se bemoeienis met die Donatiste skep die patroon vir Konstantyn se optrede in die Ooste. Dat hy daar in die kerklike sake betrokke raak, hang saam met sy stryd met sy mede-Augustus, Licinius. In die Ooste het Licinius, ondanks die edik van Milaan, tog weer oorgegaan tot die vervolging van Christene al was dit dan ook net die ontslag van alle Christene uit die staatsdiens en die verpligting dat die Christene ook aan die heidense feeste moet deelneem.

Dit skep spanninge en in 323 breek die oorlog uit teen Licinius wat eindig met sy neerlaag by Chrysopolis. Na sy oorwinning herbeklemtoon Konstantyn sy beleid ook nou wat die Ooste betref. Die Christene kry volle godsdiensvryheid en die reg om grond te besit terwyl die hele vervolgingsbeleid verwerp word. Interessant en belangrik is die stelling wat Konstantyn hier gemaak het:

„,God het my tot diens geroep en het geoordeel dat daardie diens sy doel kan dien. Beginnende in Britannia het God die magte van die kwaad vernietig sodat die mensdom, deur my bemiddeling, teruggeroep mag word na die ware godsdiens en dat die geseënde geloof onder sy hand mag uitbrei. En van die Weste het ek na die Ooste, wat 'n groter behoefte aan my hulp gehad het, gekom in die oortuiging dat hierdie gawe, om die ware godsdiens te verbrei, aan my toevertrou is. Terselfdertyd is ek vas daarvan oortuig dat ek my hele lewe, my elke asemtog, in een woord, my mees geheime gedagtes, aan die oppermagtige God dank."

Hier sien Konstantyn homself as 'n geroepe dienskneg, draer, verbreider en beskermer van die ware godsdiens. Daarom is dit ook nie vreemd dat hy, waar hy aanvanklik die heidendom verdra het, later ook oorgaan tot die onderdrukking van die heidendom nie. Konstantyn se godsdienstige beleid is ' $n$ direkte bevordering van die Christendom met as doelwit die vereniging van die Romeinse ryk met die Christelike kerk.

Wanneer Konstantyn in die Ooste orde geskep het, word dit vir hom duidelik dat die kerk daar ernstig verdeel is oor die hele Ariaanse kwessie. Dit het nie in die lyn van Konstantyn se denke gelê om hierdie saak so te laat nie.

\section{Konstantyn en die Konsilie van Nicea}

Toe Konstantyn bewus word van die Ariaanse stryd, stuur hy sy raadgewer, biskop Ossius van Corduba, na Alexandrië met 'n brief vir biskop Alexander en die presbyter Arius. Ook hierdie skrywe 
is van belang, want daarin stel Konstantyn dat hy al sy onderdane in een gemeenskaplike geloof wil verenig omdat dit ook die belang van die ryk sal dien. Dan bieci Konstantyn aan om in hierdie stryd te bemiddel want dit is net moontlik dat hy, die dienskneg van God, geroep mag wees om die strydende partye weer met mekaar te versoen.

Biskop Ossius sc poging het egter misluk en 'n sinode van biskoppe wat te Antiochië byeen was, veroordeel Arius. Daar word dan ook bepaal dat 'n groter en talryker vergadering te Ancyra, die setel van Marcellus, wat 'n verbete teenstander van Arius is, byeen sal kom om die saak verder te beoordeel. Op die manier sou die keiser self nie aan bod kom nie. Maar dan gryp Konstantyn in en bepaal dat 'n Konsilie, verteenwoordigend van die hele kerk, te Nicea byeen moet kom om oor dié aangeleentheid te handel. Hoewel Konstantyn nie die gang van sake wil dikteer nie, is sy invloed nie gering nie. Enersyds stel Konstantyn: ${ }^{10}$ )

„Ek is maar 'n gewone mens, daarom sal dit 'n onreg teenoor God wees as ek 'n regterlike posisie vir myself in hierdie saak sou aanmatig, want die klaers en die aangeklaagdes is biskoppe."

Aan die ander kant weer stel Konstantyn in sy skrywe aan die biskoppe wat die Konsilie nie kon bywoon nie:11)

"Aangesien ek uit die welvaart van die ryk ervaar het hoe groot die goedgesindheid van die goddelike mag is, glo ek dat die hoogste doel van die Konsilie was om een, enkelvoudige geloof en een openhartige liefde en een eensgesinde verering van die almagtige God te bewaar. Aangesien in hierdie saak geen onveranderlike en duursame reëling getref kan word nie tensy alle of minstens die meeste biskoppe byeen is om so ' $n$ beslissing te gee nie, daarom is alle biskoppe uitgenooi en het ek self saam met hulle, soos een van $u$, vergader want dit mag ek nie wegsteek nie, wat my besondere vreugde verskaf, dat ek u mede-dienskneg is."

Hoewel maar „'n gewone mens" sien Konstantyn homself tog as 'n mede-dienskneg van die biskoppe. Die keiser is dus ook 'n biskop. Dit is maar 'n paar stappies verwyder van die gedagte dat die keiser die pontifex maximus is, dat die kerk 'n stutorganisasie van die ryk is, dat die kerk on Jergeskik aan die belange van die ryk is, soos ons dit by Justinianus aantref.

As dit skerp besien word, kan gestel word dat vir Konstantyn die oorheersende belang in sy lewe die eenheid, voorspoed en veiligheid van sy ryk is. Alles word aan daardie ideaal diensbaar

10) Sozomenos, Historia, I, 17.

11) Eusebius, Vita, II, 17. 
gemaak. Dat Arius se leer die wesenlike van die Christelike geloof aantas en dat dit daarom vir die kerk 'n ernstige gevaar inhou, het Konstantyn waarskynlik nooit voldoende besef nie. Die Ariaanse stryd skep verdeeldheid en dié verdeelheid moet ter wille van die rykseenheid besweer word. Dit gaan vir Konstantyn nie so seer om die waarheid nie as wel orr die eenheid en die eensgesindheid, soos hy so duidelik in sy skrywe aan biskop Alexander en presbyter Arius gestel het. ${ }^{12}$ )

So kom die 318 biskoppe, ongeveer een-sesde van die totale aantal diensdoende biskoppe van die Christelike kerk, te Nicea onder voorsitterskap van die keiser byeen. Vir die biskoppe gaan dit om die waarheid, na aanleiding van Arius se opvattinge. Vir Konstantyn gaan dit om die eenheid van die kerk ter wille van die ryk.

Die Ariaanse stryd het vir die biskoppe 'n groot probleem geskep, want die meerderheid van die biskoppe was nie Ariaans nie en het Arius se opvattings hartgrondig verwerp. Dit beteken egter dat die Konsilie iets meer moes doen as om net die konklusies wat die Ariane trek uit hulle interpretasie van die Skrif, af te wys. 'n Positiewe uiteensetting van wat die kerk geglo het, was noodsaaklik. Maar nou was die meeste biskoppe onwillig om 'n nuwe terminologie te skep, 'n terminologie wat nóg deur die tradisie nóg deur die woordgebruik van die apostels aanvaarbaar gemaak is. Maar al die Skriftuurlike omskrywings is deur die Ariane aanvaar omdat hulle daaraan hulle eie uitleg kon vasknoop.

Eers is ' $n$ duidelike Ariaanse formulering verwerp en dan lees Eusebius van Caesarea ' $n$ doopbelydenis van sy gemeente voor wat aanvaarbaar geag word, behalwe dat dit nie eksplisiet genoeg is op dié punte waarom dit gaan nie. Dan stel die keiser, waarskynlik voorgesê deur biskop Ossius of ' $n$ ander lid van die Alexandrynse groep, die woord homo-ousios voor. Die aanvaarding van die begrip lei tot ' $n$ paar verdere, klein wysigings in die geloofsbelydenis. Die geloofsbelydenis word dan afgesluit met ' $n$ aantal anathemas teen die Ariane. Al die biskoppe behalwe Secundus en Theonas het die geloofsbelydenis van Nicea onderteken en as daarop 'n keiserlike bevel volg wat Arius verban. wil dit voorkom asof die Ariaanse kwessie inderdaad met $n^{\circ}$ minimum van onderlinge verskil afgehandel is.

Dit was egter nie die geval nie en eers met die Konsilie van Konstantinopel in 381 , sou daar werklike aanvaarding wees. Wat by Nicea gebeur het, was dat die relatiewe klein groep Alexandryne deur hulle teologiese bedrewenheid en skranderheid 'n oorwinning behaal oor die Ariane met behulp van die groot middegroep wat, soos dikwels met in middegroep gebeur, nie presies geweet het

12) Eusebius, Vita, II, 64, 72. 
waarom dit alles gaan nie. Die besware van hierdie middegroep was teen die gebrulk van nuwe, on-Skriftuurlike begrippe wat nie deur die oorlewering gesanksioneer is nie. Hoewel die meeste die Arianisme verwerp, was die toetssteen van 'n belydenis iets nuuts en baie van die middegroep biskoppe was nie oortuig dat die belydenis van Nicea inderdaad die antwoord op die Arianisme was $n i e$. Die gevolg is ' $n$ reaksie ten gunste van Arius en ' $n$ vyandskap teen Athanasius en Marcellus en ' $n$ voortgaande stryd wat eers in 381 by Konstantinopel finaal afgehandel word.

So het die groot Konsilie dan plaasgevind en is rondom Arius en nog talle ander sake, o.a. die vasstelling van die datum van Paasfees, beslissings geneem onder voorsitterskap van die keiser. Kerk en kroon, so wil dit voorkom, het saam geseëvier en op dié twee pilare sou die ryk in vrede en orde kon rus. Maar so sou dit tog nie wees nie en die idilliese toneeltjie van die keiserlike feesmaal tydens die Konsilie, is relatief gou versteur.

\section{Na die Konsilie}

Die eerste faktor wat die vrede versteur, is dat die keiser, beïnvloed deur sy suster, Constantia, 'n ondersteuner word van Eusebius van Caesarea en sy groep in die kerk omdat hierdie groep weer bereid is om die schismatici wat berou betoon, in die gemeenskap van die kerk terug te ontvang. Uiteraard het hierdie groep, met sy inklusiewe tendens, ook nader aan Konstantyn gestaan, want hy wat homself noem ,biskop van die sake rondom die kerk", wil vrede in die kerk hê ter wille van sy ryk. Maar daarmee kom Konstantyn onherroeplik in botsing met sy vroeëre hof-biskop Ossius én Athanasius wat geen keiserlike inmenging in die kerk wil duld nie, wat die vryheid van die kerk, ook teenoor die keiser, wil handhaaf. Dat dit vir Ossius, maar veral vir Athanasius, 'n lydensweg beteken, spreek byna vanself. Konstantyn, die religiosissimus Augustus, wat aan die kerk sy aardse bestaansreg binne die Romeinse ryk gegee het, word nou die keiser wat die nuutgevonde vryheid van die kerk in sacra bedreig.

Relatief kort na die Konsilie van Nicea besoek Arius self die keiser en verseker die keiser dat hy nou dieselfde geloof as wat by Nicea bely is, aanvaar. Dit bring die keiser daartoe om in 'n skrywe aan Alexander aan te beveel dat Arius weer in die gemeenskap van die kerk opgeneem moet word. Maar die Alexandryne vertraag die uitvoering van die keiser se versoek. In 'n skrywe na 330 stel die keiser aan Athanasius: ${ }^{13}$ )

13) Athanasius, Apologia contra Arianos, 59. 
„Nou weet u wat ek wens: aan almal wat tot die kerk wil toetree moet $u$ vrye ingang gee. Want indien ek hoor dat $u$ enigiemand wat die geloof van die kerk aanvaar, verninder of dat $u$ sodanige persone verhinder om tot die kerk toe te tree, sal ek onmiddellik iemand stuur wat op my bevel u sal afsit en $u$ in ballingskap sal stuur."

Hier word dit duidelik dat Konstantyn se bekommernis alleen rondom die eenheid van die kerk lê, dit wat dienstig is aan die belange van die ryk, en dat hy geen oog het vir die waarheid wat vir die kerk van primêre belang is nie.

Tog tree Konstantyn nie so drasties op nie, en in 335 belê hy 'n sinodale vergadering te Tirus om die stryd tussen Athanasius en die volgelinge van Eusebius te bespreek en te besleg. In sy uitnodigingsgeskrif gaan dit weer vir Konstantyn om die eenheid van die kerk en daarin sê die keiser baie pertinent: ${ }^{14}$ )

„Laat daar dan geen vertragings van u kant wees nie. Ek het instruksies gegee dat daardie biskoppe teenwoordig moet wees wat volgens $u$ wens aan hierdie beraad deel rroet hê, en as enigiemand - wat ek nie verwag nie ons oproep sou ignoreer, dan sal ek iemand stuur wat op my bevel so ' $n$ biskop sal uitdryf en hom sal leer dat dit nie paslik is om 'n keiserlike bevel, wat ten dienste van die waarheid uitgevaardig is, so te weerstaan nie."

Hierdie sinode het -nie sonder haat of partydigheid, soos die opdrag was, geoordeel nie maar Athanasius veroordeel en dié veroordeling is opgevolg deur 'n keiserlike verbanningsbevel. So word die keiser, die biskop van die sake rondom die kerk, ook 'n biskop binne die kerk. Die biskoppe sien in hulle haat teen Athanasius nie in nie dat hulie, juis deur hulleself aan die keiser diensbaar te maak, die vryheid van die kerk opoffer nie, dat hulle besig is om die kerk in 'n gevaarliker posisie te laat beland as in die dae toe die keiser openlik en vyandig as 'n vervolger teenoor die kerk gestaan het.

\section{Slotopmerkings}

Een saak is dadelik duidelik en dit is dat keiser Konstantyn dwarsdeur sy regering hom geassosieer het met die Christendom, met die Christelike kerk en die Christelike geloofsbelydenis. Daarby het hy die idee van geroepenheid gehad om die Christendom uit te brei ook na die heidene toe.

Dit het egter vir Konstantyn beteken dat hy ook 'n taak ten opsigte van die kerk gehad het. Hierdie taak sien hy as die noodsaaklike handhawing van die eenheid van die kerk want dit is vir

14) Eusebius, Vita, IV, 42. 
hom die waarborg vir die voortgaande voorspoed van die Romeinse ryk. As God die ryk beskerm, dan, so sien Konstantyn dit, moet keiser en kerk in antwoord op daardie beskerming, die eenheid ten alle koste bewaar. So word in hierdie proses die waarheid die slagoffer van die eenheid.

As Konstantyn in 337 sterf, word hy op sy sterfbed gedoop deur die Arianiserende biskop Eusebius terwyl hy terselfdertyd sy lojaliteit aan die leer van die kerk bevestig. So sterf Konstantyn, die keiser wat aan die kerk vryheid gegee het en hy laat dit aan sy seun, die 21-jarige Constantinus, om die vrugte van sy beleid te pluk nl. die stryd tussen die keiser en die kerk.

Die idilliese beeld van Nicea waar die keiser en die biskoppe op dieselfde kussings aanlê by 'n feesmaal, het verdwyn omdat nóg die keiser nóg die biskoppe die eiesoortigheid of die vryheid van die kerk gerespekteer het. 